\title{
Development and validation of a prognostic nomogram in lung cancer with obstructive sleep apnea syndrome
}

\author{
kehu (D 404793938@qq.com ) \\ Wuhan University \\ Wei Liu \\ Wuhan University \\ xiaofeng wu \\ Wuhan University \\ ling zhou \\ Tongji Hospital
}

\section{Research Article}

Keywords: OSA, Lung cancer, Prognosis, Nomogram

Posted Date: May 13th, 2021

DOl: https://doi.org/10.21203/rs.3.rs-495283/v1

License: (c) (i) This work is licensed under a Creative Commons Attribution 4.0 International License. Read Full License 


\section{Abstract \\ Background}

To analyze the prognostic factors and survival rate of lung cancer patients with OSA by nomogram.

\section{Methods}

We developed and validated a nomogram to help improve prediction of overall survival in Lung cancer patients with OSA. The nomogram was established by a development cohort $(n=90)$, and the validation cohort included 38 patients. Factors in the nomogram were identified by Cox hazard analysis. We tested the accuracy of the nomograms by discrimination and calibration, and plotted decision curves to assess the benefits of nomogram-assisted decisions. At last we evaluated the risk in the two cohort.

\section{Results}

There were significant difference in sex, AHI, TNM stage, coronary heart disease, LSp02, T90\%, TS90\% and ODI4 between lung cancer subgroup and lung cancer with OSA subgroup $(P<0.05)$. Lung cancer patients with OSA age $(P=0.021), \operatorname{AHI}(P=0.006)$, $\operatorname{TNM}$ stage $(P=0.005)$, cancer types $(P=0.038), B M I(P=$ $0.007)$ and were independent prognostic factor. Based on these six factors, a nomogram model was established. The c-index of internal verification was $0.802(95 \% \mathrm{Cl} 0.767-0.885) \square$ The ROC curve analysis for the nomogram show 1-year survival (AUC $=0.827$ ), 3-year survival (AUC $=0.867)$, 5-year survival (AUC $=0.801)$ in the development cohort and 3-year survival $(A U C=0.863)$ in the validation cohort is with good accuracy. The calibration curve shows that the survival probability of this prediction model is in good agreement with the actual situation at 1,3 and 5 years with good consistency. decision curve analysis(DCA)suggests that the net benefit of decision-making with this nomogram is higher, especially in the probability interval of $<20 \%$ threshold.

\section{Conclusions}

Age, AHI,TNM stage, cancer types, BMI and ODI4 are independent risk factors for prognosis of lung cancer patients with OSASロthe nomogram can predict the prognosis of patients and guide individualized treatment.

\section{Introduction}

Lung cancer is the leading cause of cancer death in the world, at present, the pathogenesis of lung cancer is not clear. sleep apnea syndrome (SAS) is a disease with high incidence rate and serious harm to human health, obstructive sleep apnea syndrome (OSAS) accounts for more than $90 \%$ of SAS ${ }^{[1]}$. OSA is an independent risk factor of multiple system chronic diseases such as hypertension, coronary heart 
disease, arrhythmia and stroke ${ }^{[2]} \llbracket \mathrm{OSA}$ also has a unique role in promoting tumor growth and plays an important role in the occurrence and development of tumors ${ }^{[3]}$, lung cancer is the most closely related malignant tumor with OSA ${ }^{[4]}$.

Now through the comprehensive treatment of lung cancer, the survival rate has been significantly improved. Improving the quality of life, especially sleep quality is very important for lung cancer patients. It not only helps to accelerate the physical and mental recovery, but also increases the body's immunity and resistance. Lung cancer is very common in OSA patients, OSA is usually moderate or severe at the time of diagnosis, lung cancer and intermittent hypoxia, apnea, daytime sleepiness forming a vicious

cycle『results the quality of life decreased significantly, and the survival time decreased ${ }^{[5]}$.

Currently, nomograms have been developed in the majority of cancer types ${ }^{[6-8]}$, in this study, we aimed to develop and validate a prognostic nomogram that uses widely available general data and laboratory indicator to improve our ability to predict survival time of Lung cancer patients with OSA.

\section{Methods}

\section{Patient selection}

The retrospectively study included 410 lung cancer patients from 2013 to 2016 in Renmin Hospital of Wuhan University and Tongji Hospital囚all subjects received philips YZB/USA 1575-2013 portable sleep recorder to monitor patients' sleep for at least $7 \mathrm{~h}$ per night, there are 128 cases diagnosis of OSA, The inclusion criteria were as follows: (1)the pathological diagnosis was confirmed as lung malignant tumor区 (2)normal range of blood pressure in patients with hypertension after use of antihypertensive treatment, and no hypertension-related complications; after symptomatic treatment, the patients with CHD were stable without complications; the blood glucose level in patients with type 2 diabetes without complications was normal after treatment; (3) no drugs possibly influencing the sleep patterns were currently being taken.

The patients suffering from the following diseases or lesions were excluded: infectious diseases, intracranial lesions, pulmonary embolism, rheumatic diseases and other diseases that may cause abnormal blood oxygen saturation. This study was conducted in accordance with the Declaration of Helsinki.

\section{Laboratory measurements}

All subjects received philips YZB/USA 1575-2013 portable sleep recorder to monitor patients' sleep for at least $7 \mathrm{~h}$ per night, all data previously listed were played back, analyzed by a computer, and corrected artificially. The data about apnea hypopnea index (AHI), oxygen desaturation index (ODI4), lowest arterial oxygen saturation [LSpO2 (\%)], oxygen below 90\% of the time [T90\% (min)], and the percentage of the 
total recorded time spend below $90 \%$ oxygen saturation (TS90\%) were obtained. All the patients datas were record when the first time of hospitalizations, clinical information was extracted from Electronic Medical Record system. All the patients received routine tests at the first visit in our hospital.

\section{Follow-Up}

patients were advised to receive regular follow-ups after completion of the primary therapy according to clinical guidelines. Patients were generally followed up every 3 months in the first 2 years and annually thereafter for patients without evidence of recurrence in the following 3 to 5 years. OS was defined as the time from the diagnosis of lung cancer to the date of the last follow-up or death ,the outcome of our study was overall survival (OS) \The follow-up deadline was November 1, 2020.

\section{Statistical analysis}

Statistical analyses were performed using SPSS 25.0 (IBM, Chicago, IL, USA) and R for Windows (version3.4.2, http://www.r-proje ct.org/). The optimal cut-off points in our study were evaluated by minimum $P$ value from log-rank $\times 2$ statistics using the $X$-tile program ${ }_{[9]}$ and continuous variables were transformed to categorical variables, regression analysis was used to analyze the risk factors in the development cohort, A nomogram was formulated based on the results of univariate and multivariate analysis by the package of rms. We tested the accuracy of the nomograms by discrimination and calibration both in primary and externa validation cohort. The discrimination of the nomogram was measured by Harrell's C-index (C-index). the calibration curve of the nomogram model for the overall survival were formulated. The total points of each patient were calculated according to the established Cox regression model. Survival curves were depicted by the Kaplan-Meier method. A two-sided $\mathrm{P}<0.05$ was considered statistically significant.

\section{Results}

\section{Clinical Characteristics of All patients}

The clinical characteristics of All patients were evaluated. The characteristics of the 282 lung cancer patients and 128 lung cancer patients with OSA are showed in Table 1. The median age was 59.98 years, and only 172 patients (42.0\%) were female. Among the 410 patients, there were 73 patients with the small cell carcinoma (17.8) and 337 patients with the non-small cell carcinoma (82.2\%). There was significant difference in sex, AHI, TNM stage, coronary heart disease, LSpO2, T90\%, TS90\% and ODI4 between lung cancer subgroup and lung cancer with OSA subgroup $(P<0.05)$. 
Table 1

baseline clinical features of all patients(Mean \pm SD/No (\%))

\begin{tabular}{|c|c|c|c|c|c|}
\hline Characteristics & $\begin{array}{l}\text { Total } \\
(n=410)\end{array}$ & $\begin{array}{l}\text { Lung cancer } \\
(n=282)\end{array}$ & $\begin{array}{l}\text { Lung cancer with } \\
\text { OSA } \\
(n=128)\end{array}$ & Statistics & $\mathbf{P}$ \\
\hline Age,year & $59.98 \pm 3.22$ & $59.53 \pm 3.53$ & $60.98 \pm 2.45$ & $1.432 *$ & 0.853 \\
\hline Sex & & & & $6.382^{+}$ & 0.011 \\
\hline Male & 238(58.0) & 152(53.9) & $86(67.2)$ & & \\
\hline Female & $172(42.0)$ & $130(46.1)$ & $42(32.8)$ & & \\
\hline $\mathrm{AHI}$ & $4.35 \pm 2.01$ & $2.54 \pm 2.03$ & $9.87 \pm 1.98$ & $0.637^{*}$ & 0.001 \\
\hline TNM stage & & & & $11.860^{+}$ & 0.008 \\
\hline I & $129(31.5)$ & $95(33.7)$ & $34(26.6)$ & & \\
\hline II & $147(35.9)$ & 102(36.2) & $45(35.2)$ & & \\
\hline III & $83(20.2)$ & $45(16.0)$ & $38(29.7)$ & & \\
\hline IV & $51(12.4)$ & $40(14.2)$ & $11(8.5)$ & & \\
\hline Cancer types & & & & $1.115^{\dagger}$ & 0.291 \\
\hline Small cell carcinoma & 73(17.8) & $54(19.1)$ & 19(14.8) & & \\
\hline $\begin{array}{l}\text { non-Small cell } \\
\text { carcinoma }\end{array}$ & $337(82.2)$ & 228(80.9) & 109(85.2) & & \\
\hline BMI & $20.88 \pm 1.78$ & $20.43 \pm 1.54$ & $21.90 \pm 2.98$ & $1.445^{*}$ & 0.384 \\
\hline Hypertension & $128(31.2)$ & $84(29.8)$ & $44(34.4)$ & $0.863^{\dagger}$ & 0.353 \\
\hline Diabetes & $144(35.1)$ & $102(36.2)$ & $42(32.8)$ & $0.435^{\dagger}$ & 0.509 \\
\hline Coronary heart disease & $64(15.6)$ & $37(13.1)$ & $27(21.2)$ & $4.249^{\dagger}$ & 0.039 \\
\hline Heart rate,beats/min & $\begin{array}{l}91.76 \pm \\
20.34\end{array}$ & $\begin{array}{l}91.43 \pm \\
21.54\end{array}$ & $92.34 \pm 17.92$ & $1.432^{*}$ & 0.758 \\
\hline KPS & $\begin{array}{l}80.23 \pm \\
12.44\end{array}$ & $\begin{array}{l}82.34 \pm \\
13.54\end{array}$ & $76.34 \pm 8.342$ & $0.552^{*}$ & 0.817 \\
\hline Smoking history & 167(40.7) & 110(39.0) & $57(44.5)$ & $1.113^{\dagger}$ & 0.292 \\
\hline
\end{tabular}




\begin{tabular}{|c|c|c|c|c|c|}
\hline Characteristics & $\begin{array}{l}\text { Total } \\
(n=410)\end{array}$ & $\begin{array}{l}\text { Lung cancer } \\
(n=282)\end{array}$ & $\begin{array}{l}\text { Lung cancer with } \\
\text { OSA } \\
(n=128)\end{array}$ & Statistics & $\mathbf{P}$ \\
\hline LSpO2 (\%) & $\begin{array}{l}78.32 \pm \\
10.23\end{array}$ & $\begin{array}{l}87.32 \pm \\
15.64\end{array}$ & $69.43 \pm 6.31$ & $1.954 *$ & 0.009 \\
\hline T90\%,min & $56.34 \pm 3.41$ & $23.43 \pm 1.65$ & $91.23 \pm 4.43$ & $1.943 *$ & 0.001 \\
\hline TS90\%, \% & $9.32 \pm 2.01$ & $1.32 \pm 1.03$ & $22.41 \pm 2.89$ & $3.215^{*}$ & 0.001 \\
\hline ODI4 & $0.45 \pm 0.19$ & $0.23 \pm 0.08$ & $1.98 \pm 0.28$ & $1.344^{*}$ & 0.001 \\
\hline \multicolumn{6}{|c|}{$\begin{array}{l}\text { Data were shown as mean } \pm \text { standard deviation, } n(\%) . *_{t} \text { test, }{ }^{\dagger} \times 2 \text { value. AHI: apnea hypopnea index; } \\
\text { BMI: body mass index; LSpO2 }(\%): \text { lowest arterial oxygen saturation; T90\%: oxygen below } 90 \% \text { of the } \\
\text { time; TS90\%: the percentage of the total recorded time spend below } 90 \% \text { oxygen saturation; ODI4: } \\
\text { oxygen desaturation index }\end{array}$} \\
\hline
\end{tabular}

\section{Clinical Characteristics of Lung cancer patients with OSA}

The clinical characteristics of the training and validation sets were evaluated. The characteristics of the 90 patients in the development cohort and 38 patients in the validation cohort are showed in Table 2. The majority of patients are men and patients of TNM stages were represented, there were no statistically significant difference in development cohort and validation cohort. 
Table 2

baseline clinical features of Lung cancer patients with OSA(Mean \pm SD/No (\%))

\begin{tabular}{|c|c|c|c|c|c|}
\hline Characteristics & $\begin{array}{l}\text { Total } \\
(n=128)\end{array}$ & $\begin{array}{l}\text { Development } \\
\text { cohort } \\
(n=90)\end{array}$ & $\begin{array}{l}\text { Validation } \\
\text { cohort } \\
(n=38)\end{array}$ & Statistics & $\mathbf{P}$ \\
\hline Age,year & $60.98 \pm 2.45$ & $60.53 \pm 2.34$ & $61 \pm 1.98$ & $1.453^{*}$ & 0.224 \\
\hline Sex & & & & $0.048^{\dagger}$ & 0.827 \\
\hline Male & $86(67.2)$ & $61(67.8)$ & $25(65.8)$ & & \\
\hline Female & $42(32.8)$ & $29(32.2)$ & 13(34.2) & & \\
\hline $\mathrm{AHI}$ & $9.87 \pm 1.98$ & $9.42 \pm 1.53$ & $10.32 \pm 0.97$ & $0.634^{*}$ & 0.543 \\
\hline TNM stage & & & & $2.460^{\dagger}$ & 0.483 \\
\hline I & $34(26.6)$ & $23(25.6)$ & 11(28.9) & & \\
\hline II & $45(35.2)$ & $31(34.4)$ & 14(36.8) & & \\
\hline III & $38(29.7)$ & $26(28.9)$ & 12(31.6) & & \\
\hline IV & $11(8.5)$ & 10(11.1) & $1(2.7)$ & & \\
\hline Cancer types & & & & $0.547^{\dagger}$ & 0.460 \\
\hline Small cell carcinoma & 19(14.8) & $78(86.7)$ & $31(82.6)$ & & \\
\hline $\begin{array}{l}\text { non-Small cell } \\
\text { carcinoma }\end{array}$ & $109(85.2)$ & 12(13.3) & $7(18.4)$ & & \\
\hline BMI & $21.90 \pm 2.98$ & $22.74 \pm 3.42$ & $21.45 \pm 2.54$ & $1.425^{*}$ & 0.628 \\
\hline Hypertension & $44(34.4)$ & $31(34.5)$ & 13(34.2) & $0.001^{\dagger}$ & 0.979 \\
\hline Diabetes & $42(32.8)$ & $30(33.3)$ & 12(31.6) & $0.037^{\dagger}$ & 0.847 \\
\hline Coronary heart disease & $27(21.2)$ & $20(22.2)$ & $7(18.4)$ & $0.232^{\dagger}$ & 0.630 \\
\hline Heart rate,beats/min & $\begin{array}{l}92.34 \pm \\
17.92\end{array}$ & $93.44 \pm 16.43$ & $91.43 \pm 13.54$ & $0.425^{*}$ & 0.087 \\
\hline KPS & $\begin{array}{l}76.34 \pm \\
8.342\end{array}$ & $74.55 \pm 9.43$ & $79.54 \pm 6.74$ & $1.445^{*}$ & 0.154 \\
\hline Smoking history & $57(44.5)$ & $42(46.7)$ & 15(39.5) & $0.559^{\dagger}$ & 0.454 \\
\hline LSpO2 (\%) & $69.43 \pm 6.31$ & $70.87 \pm 7.43$ & $68.43 \pm 5.73$ & $1.434^{*}$ & 0.563 \\
\hline
\end{tabular}

Data were shown as mean \pm standard deviation, $n(\%) .{ }^{*}$ t test, ${ }^{\dagger} \times 2$ value. 


\begin{tabular}{|llllll|}
\hline Characteristics & Total & $\begin{array}{l}\text { Development } \\
\text { cohort } \\
(\mathbf{n = 1 2 8})\end{array}$ & $\begin{array}{l}\text { Validation } \\
\text { cohort } \\
(\mathbf{n = 9 0})\end{array}$ & Statistics & $\mathbf{P}$ \\
\hline T90\%,min & $91.23 \pm 4.43$ & $87.54 \pm 3.43$ & $93.23 \pm 5.43$ & $2.543 *$ & 0.623 \\
\hline TS90\%,\% & $22.41 \pm 2.89$ & $21.75 \pm 2.54$ & $23.21 \pm 3.54$ & $1.240 *$ & 0.154 \\
\hline ODI4 & $1.98 \pm 0.28$ & $1.72 \pm 0.23$ & $2.01 \pm 0.35$ & $0.643 *$ & 0.634 \\
\hline Data were shown as mean \pm standard deviation, $n(\%) .{ }^{*}$ t test, ${ }^{+} \times 2$ value. & & \\
\hline
\end{tabular}

\section{Biomarker selection}

All the available informations, including general data, clinical characteristics and biomarkers, were included for univariate and multivariate analysis (Table 3). In univariate analyse Age, AHI, TNM stage, types, BMI, LSpO2 (\%) and ODI4 were related to OS. All of the potentially important biomarkers identified in univariate analysis were further included in the multivariate analysis. Based on 90 OSA with lung cancer patients with complete information, Age, AHI, TNM stage, types ,BMI and ODI4 were significant predictors of OS. 
Table 3

Univariate and multivariate Cox hazards analysis between clinical features and OS $(n=90)$

\begin{tabular}{|c|c|c|c|c|c|c|}
\hline & & $\begin{array}{l}\text { Univariat } \\
\text { analysis }\end{array}$ & & & $\begin{array}{l}\text { Multivariate } \\
\text { analysis }\end{array}$ & \\
\hline Variables & OR & $95 \% \mathrm{Cl}$ & $\mathrm{P}$ & OR & $95 \% \mathrm{Cl}$ & $\mathrm{P}$ \\
\hline $\operatorname{Age}(\geq 60$ vs. $<60 \square)$ & 4.523 & $\begin{array}{l}1.432- \\
7.546\end{array}$ & 0.008 & 2.543 & $\begin{array}{l}1.053- \\
5.324\end{array}$ & 0.021 \\
\hline Sex(male vs. female) & 2.435 & $\begin{array}{l}0.234- \\
3.253\end{array}$ & 0.454 & & & \\
\hline $\mathrm{AHI}(\geq 15$ vs. $<15)$ & 5.434 & $\begin{array}{l}2.432- \\
7.545\end{array}$ & 0.032 & 3.245 & $\begin{array}{l}1.323- \\
5.435\end{array}$ & 0.006 \\
\hline TNM stage ( $\geq 3$ vs. $<3$ ) & 8.655 & $\begin{array}{l}4.345- \\
9.553\end{array}$ & 0.027 & 2.431 & $\begin{array}{l}1.634- \\
4.523\end{array}$ & 0.005 \\
\hline $\begin{array}{l}\text { Cancer types(Small cell } \\
\text { carcinoma VS. non-Small cell } \\
\text { carcinoma) }\end{array}$ & 1.321 & $\begin{array}{l}1.023- \\
4.328\end{array}$ & 0.008 & 1.043 & $\begin{array}{l}1.002- \\
2.431\end{array}$ & 0.038 \\
\hline $\mathrm{BMI}(\geq 24$ VS. $<24)$ & 2.341 & $\begin{array}{l}1.453- \\
4.523\end{array}$ & 0.012 & 1.532 & $\begin{array}{l}1.332- \\
3.454\end{array}$ & 0.007 \\
\hline Hypertension (yes vs. no) & 2.412 & $\begin{array}{l}0.453- \\
4.545\end{array}$ & 0.673 & & & \\
\hline Diabetes (yes vs. no) & 1.167 & $\begin{array}{l}0.446- \\
1.438\end{array}$ & 0.098 & & & \\
\hline $\begin{array}{l}\text { Coronary heart disease (yes vs. } \\
\text { no) }\end{array}$ & 1.432 & $\begin{array}{l}0.314- \\
1.634\end{array}$ & 0.342 & & & \\
\hline $\begin{array}{l}\text { Heart rate }(<90 \text { VS. } \geq 90 \\
\text { beats } / \mathrm{min})\end{array}$ & 1.342 & $\begin{array}{l}0.754- \\
2.525\end{array}$ & 0.234 & & & \\
\hline KPS(< 90 vs $\geq 90)$. & 1.554 & $\begin{array}{l}0.186- \\
2.345\end{array}$ & 0.423 & & & \\
\hline Smoking history(yes vs. no) & 1.543 & $\begin{array}{l}0.423- \\
2.253\end{array}$ & 0.564 & & & \\
\hline LSpO2\% (60 VS. <60\%) & 1.234 & $\begin{array}{l}1.134- \\
4.323\end{array}$ & 0.006 & 1.543 & $\begin{array}{l}0.156- \\
3.234\end{array}$ & 0.078 \\
\hline T90\% $(\geq 60$ VS. $<60 \mathrm{~min})$ & 2.421 & $\begin{array}{l}0.543- \\
2.232\end{array}$ & 0.743 & & & \\
\hline TS $90 \%(\geq 80$ VS. $<80 \%)$ & 1.432 & $\begin{array}{l}0.453- \\
1.354\end{array}$ & 0.355 & & & \\
\hline $\mathrm{ODI}(\geq 15$ vs. $<15)$ & 1.543 & $\begin{array}{l}1.023- \\
4.323\end{array}$ & 0.046 & 1.554 & $\begin{array}{l}1.043- \\
2.456\end{array}$ & 0.031 \\
\hline
\end{tabular}

Development of the prediction model 
A nomogram is a graphic representation of the solution of an equation that provides a reasonable approximation of the probability of a particular outcome, nomogram was developed to predict for survival using the six independent covariates identified in the multivariate model $\square$ the mode explanatory covariables consisted of ,Age, AHI,TNM stage, types ,BMI and ODI4. A nomogram was constructed to predict 1-year, 3-year and 5-year OS (Fig. 1).

\section{Validation of the predictive accuracy of nomograms for OS}

After internal verification, the C-index of the nomogram model for OS prediction was $0.802(95 \% \mathrm{Cl}$ $0.767-0.885)$. The calibration curve illustrates how the predictions from the nomogram compare with actual outcomes for the 90 patients. The dashed line represents the performance of an ideal nomogram, in which predicted outcomes mostly match with the actual outcomes. The dots were calculated from subcohorts of our dataset and represent the performance of our nomogram based on the six biomarkers of Cox model. The calibration plot for the probability of OS at 1, 3 or 5 year after therapy showed an optimal agreement between the prediction by nomogram and actual observation. (Fig. 2)

\section{Roc of the predictive accuracy of nomograms for OS}

The ROC curve analysis for the nomogram, area under curve (AUC) is used to evaluate the accuracy of the model,the higher the AUC value, the better the model effect. results show 1-year survival (AUC = 0.827), 3-year survival (AUC $=0.867)$, 5-year survival $(A \cup C=0.801)$ in the development cohort and 3-year survival $(A \cup C=0.863)$ in the validation cohort is with good accuracy ${ }^{[10]}$. (Fig. 3)

\section{Clinical application of Prognostic Nomogram}

Decision curve analysis (DCA) is used to evaluate the predictive effect of nomogram on OS, it is very important for clinical decision-making to accurately judge the impact of clinical features and related indicators on the prognosis of lung cancer patients with OSAS ${ }^{[11}[$ Factors not related to prognosis were represented by black line, factors related to prognosis were represented by gray line,the model of nomogram represented by the blue line. results show net benefit can be obtained when make decisions by nomogram. (Fig. 4)

Using this prediction model to calculate the total score, the median of the total score of all patients was 137 , total score $>=137$ belong to high-risk group, total score $<137$ belong to low-risk group. Kaplan-Meier was used to analyze OS survival in low-risk group and high-risk group, results show there was statistically significant difference in high risk group and low risk group $(P<0.05)$, the model has good accuracy and practicability. (Fig. 5)

\section{Discussion}


Prognostic models can facilitate discussion between physicians and patients, help to identify high-risk patients individualized treatments and clinical trials can be developed, and may provide insight into the biology of disease. Nomograms have been developed to predict various clinical end points for patients with all kinds of malignancies.

In recent years, multi-national cohort studies had found that OSA increases the mortality of cancer, among which lung cancer is the most common ${ }^{[12,13]}$,Dreher et al proposed that the incidence of OSA in newly diagnosed lung cancer was $49 \%$, in which the incidence of moderate/severe OSA was $17 \%$ ${ }^{[14]}$ Perez et al proposed that the incidence of OSA in lung cancer patients was $77.5 \%$, in which moderate/severe OSA accounted for $41.1 \%{ }^{[12]}$, which is consistent with the results of this study. It was found that $31 \%$ of lung cancer had different degrees of OSA. Li et al found that the overall survival rate of lung cancer patients with severe OSA was lower than that of patients with mild OSA, suggesting that the occurrence and severity of OSA are risk factors to promote cancer development ${ }^{[15]}[$ The univariate and multivariate logistic analysis indicated that age, AHIDTNM stage, cancer types, BMI and ODI4 were risk factors for overall survival, Now studies have confirmed that age is an important factor in the occurrence of lung cancer and is an independent risk factor for survival and prognosis of lung cancer patients ${ }^{[16]}$. The incidence rate of OSA in elderly people is $24 \% \sim 62 \%$, and the severity of OSA increases with age. Another study found that the incidence rate of OSA did not increase linearly with age, but reached the peak at 55 years old, and the incidence rate increased slowly ${ }^{[17]}$ which is consistent with the results of this study. We found that age is an independent risk factor for lung cancer patients with OSA, and the nomogram score increases fastest in the age range of 50-60 years $\square$ The elderly patients with lung cancer complicated with OSA should be closely monitored to prevent the occurrence of disease-related complications.

$\mathrm{Li}$ et al reported that tumor staging is related to the severity of OSA, and jointly affect the prognosis of lung cancer patients with OSAS ${ }^{[15]}$. The American Joint Committee Cancer (AJCC) and The Union for International Cancer Control $\square$ UICC $\square$ released the eighth edition of the TNM lung cancer staging system ${ }^{[18]}$,the TNM stage is based on the latest database of The International Association for the Study of Lung Cancer (IASLC), which contains information on 94708 patients diagnosed with lung cancer from 1999 to 2010 , most of them from Asia ${ }^{[19]}$. This study explored the effect of TNM stage on the prognosis, results show TNM stage was an independent risk factor for the prognosis of lung cancer patients with OSA. In addition, the nomogram score of patients with TNM stage IV increased significantly, TNM stage was not a simple linear relationship with survival and prognosis, we should pay attention to the progress of the disease of patients with advanced lung cancer, actively treatment intervention to slow down the progress of the disease and improve the quality of life while prolonging the survival time. According to histological classification, lung cancer can be divided into small cell lung cancer (SCLC) and non-small cell lung cancer (NSCLC), non-small cell lung cancer accounts for $80 \%$ of lung cancer. After multidisciplinary comprehensive treatment in recent years, the 5-year survival rate has been greatly improved, however, only $20 \%-30 \%$ of patients are in the early stage of lung cancer when diagnosed, and most of them fail to carry out standardized treatment in time delaying the best treatment period ${ }^{[19]}$. This study 
analyzed the prognosis of lung cancer patients with OSA, results show the prognosis of patients with small cell lung cancer was poor and the survival time was significantly reduced, although small cell lung cancer had a good response to treatment, it was often too late to make radical resection.

Wisconsin Cohort results show severe sleep disordered breathing increases nearly five times death risk of cancer ${ }^{[20]}$,Lung cancer patients are more prone to intermittent hypoxia, apnea and daytime sleepiness ${ }^{[5]}[$ This study show ODI4 was an independent risk factor for lung cancer patients with OSA. Hypoxia environment plays an important role in the development of lung cancer, On the one hand, adequate oxygenation plays an important role in maintaining the normal function of cells, tissues and organs. Hypoxia is prevalent in tumor tissues, even in the absence of severe respiratory diseases. Hypoxia is the result of high proliferation rate of cancer cells, when the speed of neovascularization is slower than that of tumor growth, it can't provide the amount of oxygen for metabolism. On the other hand, lung cancer patients are prone to sleep disorders. In addition to the persistent hypoxia of tumor tissue, vascular compression also promotes intermittent hypoxia and any factors causing intermittent hypoxia and apnea can aggravate OSAS.

Apnea hypopnea index (AHI) is the basis for the diagnosis of OSA. AHI refers to the average number of apnea and hypoventilation per hour during sleep. AHI is also a standard for grading the severity of OSA. The results suggest that the higher $\mathrm{AHI}$, the lower the survival rate of lung cancer patients with OSA, and the hypoxia microenvironment promotes the growth of lung tumors. This conclusion has been confirmed by relevant studies, simulating the intermittent hypoxia in patients with OSAS induced pulmonary metastasis of melanoma ${ }^{[21]}$, other evidence also suggests that hypoxic microenvironment contributes to the development of non-small cell lung cancer ${ }^{[22]}$. In vitro studies further proved that intermittent hypoxia lung cancer cells are more resistant and more prone to metastasis ${ }^{[23]}$,indicates that lung cancer and OSAS promote each other, leading to disease progression and reduced survival. Obesity is one of the most important risk factors for OSAHS. Obesity is related to the increase of throat fat, tongue fat and volume ${ }^{[24,25]}$. Obesity patients have severe upper airway stenosis, abdominal and thoracic fat make longitudinal tracheal traction and pharyngeal wall tension weaken, chest wall compliance decreases, lung capacity decreases, aggravating the severity of OSAHS. The increase of BMI is accompanied by an increase in the incidence of respiratory events and more severe nocturnal hypoxemia [26], indicated that the higher the degree of obesity, the higher the severity of OSAHS ${ }^{[27]}$. However, there is no consensus on the prognosis of lung cancer patients with BMI. Some studies suggest that BMI affects the prognosis of lung cancer patients by influencing all aspects of physical fitness of the body [28], Others studies suggest that high BMI is closely related to the overall survival benefit of lung cancer patients ${ }^{[29]}$. But smoking is also an important confounding factor of lung cancer, so the influence of BMI on lung cancer needs to be further explored. The results of this study show BMI is an independent prognostic factor for lung cancer patients with OSA. In short, obesity not only aggravates the severity of OSA, but also reduces the survival time of lung cancer patients with OSA. Therefore, obese patients with lung cancer and OSA are at high risk of death. 
This research has some limitations. This is a single center retrospective study, the number of samples included is limited, and the follow-up time is long, so there are incomplete clinical information. Therefore, it is still necessary to carry out external verification with large sample and multi center.

In summary,age, AHILTNM stage, cancer types, BMI and ODI4 are clinical factors affecting the prognosis of lung cancer patients with OSAIThe nomogram established in this study can be used to predict the prognosis of lung cancer patients with OSA and can provide help for patients to formulate individualized treatment strategies.

\section{Declarations}

\section{Compliance with ethical standards}

\section{Disclosure of potential conflicts of interest}

All authors declare that they have no conflict of interest.

\section{Research involving human participants and/or animals}

The manuscript contain clinical studies and patient data. it's a retrospective study study and received ethical approval from the WuHan universitiy Institutional.

\section{Informed consent}

This is a retrospective study, informed consent was obtained from all individual participants (or their families ) included in the study.

\section{Funding}

This work was supported by the National Natural Science Foundation of China (No. 81970082, 81770089).

\section{References}

1. Zhao, G. Q. et al. Za Zhi. 32 (1), 12-1722 https://doi.org/10.13201/j.issn.1001-1781.2018.01.003 (2018). [Differential evaluation of diagnostic criteria for pediatric obstructive sleep apnea hypopnea syndrome][J]. Lin Chung Er Bi Yan Hou Tou Jing Wai Ke

2. Molero-Ramirez, H. et al. Polysomnography Parameters Assessing Gas Exchange Best Predict Postoperative Respiratory Complications Following Adenotonsillectomy in Children With Severe OSA[J]. J Clin Sleep Med. 15 (9), 1251-1259 https://doi.org/10.5664/jcsm.7914 (2019).

3. Huang, H. Y. et al. Severe OSA associated with higher risk of mortality in stage III and IV lung cancer[J]. J Clin Sleep Med. 16 (7), 1091-1098 https://doi.org/10.5664/jcsm.8432 (2020). 
4. Justeau, G. et al. Chest. https://doi.org/10.1016/j.chest.2020.06.055 (2020). Association Between Nocturnal Hypoxemia and Cancer Incidence in Patients Investigated for OSA: Data From a Large Multicenter French Cohort[J]

5. Liu, W. et al. Relationship between Occurrence and Progression of Lung Cancer and Nocturnal Intermittent Hypoxia, Apnea and Daytime Sleepiness[J]. Curr Med Sci. 39 (4), 568-575 https://doi.org/10.1007/s11596-019-2075-6 (2019).

6. International Bladder Cancer et al. Postoperative nomogram predicting risk of recurrence after radical cystectomy for bladder cancer[J]. J Clin Oncol. 24 (24), 3967-3972 https://doi.org/10.1200/JC0.2005.05.3884 (2006).

7. Karakiewicz, P. I. et al. Multi-institutional validation of a new renal cancer-specific survival nomogram[J]. J Clin Oncol. 25 (11), 1316-1322 https://doi.org/10.1200/JC0.2006.06.1218 (2007).

8. Wierda, W. G. et al. Prognostic nomogram and index for overall survival in previously untreated patients with chronic lymphocytic leukemia[J]. Blood. 109 (11), 4679-4685 https://doi.org/10.1182/blood-2005-12-051458 (2007).

9. Camp, R. L., Dolled-Filhart, M. \& Rimm, D. L. X-tile: a new bio-informatics tool for biomarker assessment and outcome-based cut-point optimization[J]. Clin Cancer Res. 10 (21), 7252-7259 https://doi.org/10.1158/1078-0432.CCR-04-0713 (2004).

10. Walker, S. P. The ROC Curve Redefined - Optimizing Sensitivity (and Specificity) to the Lived Reality of Cancer[J]. N Engl J Med. 380 (17), 1594-1595 https://doi.org/10.1056/NEJMp1814951 (2019).

11. Baker, S. G. Decision Curves and Relative Utility Curves[J]. Med Decis Making. 39 (5), 489-490 https://doi.org/10.1177/0272989X19850762 (2019).

12. Perez-Warnisher, M. T. et al. Sleep disordered breathing and nocturnal hypoxemia are very prevalent in a lung cancer screening population and may condition lung cancer screening findings: results of the prospective Sleep Apnea In Lung Cancer Screening (SAILS) study[J]. Sleep Med. 54, 181-186 https://doi.org/10.1016/j.sleep.2018.10.020 (2019).

13. Martinez-Garcia, M. A. et al. Association between sleep disordered breathing and aggressiveness markers of malignant cutaneous melanoma[J]. Eur Respir J. 43 (6), 1661-1668 https://doi.org/10.1183/09031936.00115413 (2014).

14. Dreher, M. et al. Sleep-disordered breathing in patients with newly diagnosed lung cancer[J]. BMC Pulm Med. 18 (1), 72 https://doi.org/10.1186/s12890-018-0645-1 (2018).

15. Li, L. et al. Target of obstructive sleep apnea syndrome merge lung cancer: based on big data platform[J]. Oncotarget. 8 (13), 21567-21578 https://doi.org/10.18632/oncotarget.15372 (2017).

16. Choi, W. I. et al. Higher Age Puts Lung Cancer Patients at Risk for Not Receiving Anti-cancer Treatment[J]. Cancer Res Treat. 51 (3), 1241-1248 https://doi.org/10.4143/crt.2018.513 (2019).

17. Bixler, E. O. et al. Effects of age on sleep apnea in men: I. Prevalence and severity[J]. Am J Respir Crit Care Med. 157 (1), 144-148 https://doi.org/10.1164/ajrccm.157.1.9706079 (1998).

18. Kay, F. U. et al. Revisions to the Tumor, Node, Metastasis staging of lung cancer (8(th) edition): Rationale, radiologic findings and clinical implications[J]. World J Radiol. 9 (6), 269-279 
https://doi.org/10.4329/wjr.v9.i6.269 (2017).

19. Yang, L. et al. Evaluation of the 7(th) and 8(th) editions of the AJCC/UICC TNM staging systems for lung cancer in a large North American cohort[J]. Oncotarget. 8 (40), 66784-66795 https://doi.org/10.18632/oncotarget.18158 (2017).

20. Shimoda, L. A. \& Semenza, G. L. HIF and the lung: role of hypoxia-inducible factors in pulmonary development and disease[J]. Am J Respir Crit Care Med. 183 (2), 152-156 https://doi.org/10.1164/rccm.201009-1393PP (2011).

21. Almendros, I. et al. Intermittent hypoxia-induced changes in tumor-associated macrophages and tumor malignancy in a mouse model of sleep apnea[J]. Am J Respir Crit Care Med. 189 (5), 593-601 https://doi.org/10.1164/rccm.201310-18300C (2014).

22. Giovannetti, E. et al. Role of CYB5A in pancreatic cancer prognosis and autophagy modulation[J]. $J$ Natl Cancer Inst. 106 (1), djt346 https://doi.org/10.1093/jnci/djt346 (2014).

23. Liu, Y. et al. Effect of chronic intermittent hypoxia on biological behavior and hypoxia-associated gene expression in lung cancer cells[J]. J Cell Biochem. 111 (3), 554-563 https://doi.org/10.1002/jcb.22739 (2010).

24. Isono, S. Obesity and obstructive sleep apnoea: mechanisms for increased collapsibility of the passive pharyngeal airway[J]. Respirology. 17 (1), 32-42 https://doi.org/10.1111/j.14401843.2011.02093.x (2012).

25. Pahkala, R. et al. The impact of pharyngeal fat tissue on the pathogenesis of obstructive sleep apnea[J]. Sleep Breath. 18 (2), 275-282 https://doi.org/10.1007/s11325-013-0878-4 (2014).

26. Aihara, K. et al. Analysis of anatomical and functional determinants of obstructive sleep apnea[J]. Sleep Breath. 16 (2), 473-481 https://doi.org/10.1007/s11325-011-0528-7 (2012).

27. Jeong, J. I. et al. Impact of gender and sleep position on relationships between anthropometric parameters and obstructive sleep apnea syndrome[J]. Sleep Breath. 21 (2), 535-541 https://doi.org/10.1007/s11325-016-1413-1 (2017).

28. Oldenburg, C. S. et al. The relationship of body mass index with quality of life among endometrial cancer survivors: a study from the population-based PROFILES registry[J]. Gynecol Oncol. 129 (1), 216-221 https://doi.org/10.1016/j.ygyno.2012.12.041 (2013).

29. Sepesi, B. et al. The Influence of Body Mass Index on Overall Survival Following Surgical Resection of Non-Small Cell Lung Cancer[J]. J Thorac Oncol. 12 (8), 1280-1287 https://doi.org/10.1016/j.jtho.2017.05.010 (2017).

\section{Figures}




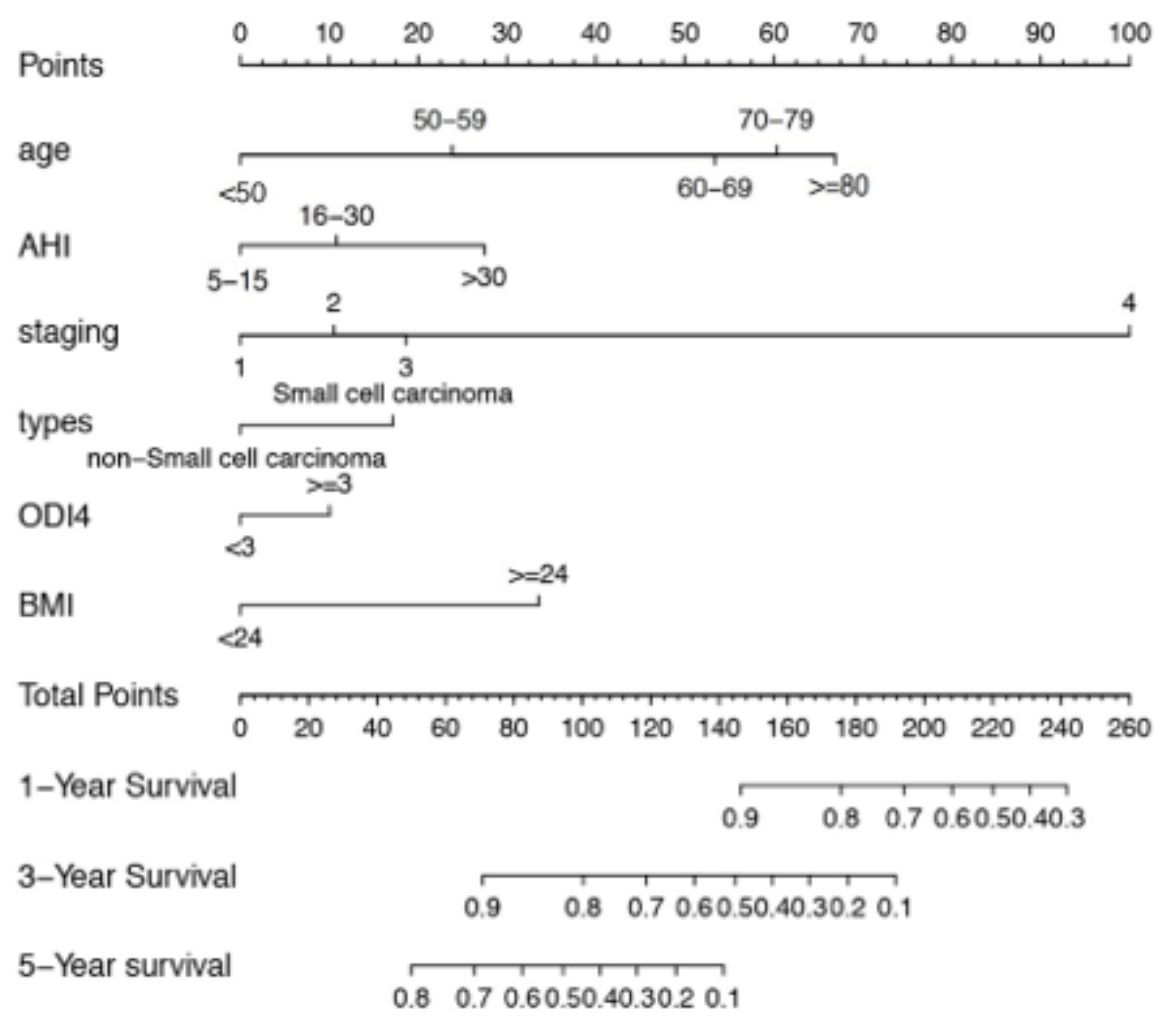

\section{Figure 1}

Nomogram, including Age, AHI, TNM stage, types, BMI and ODI4 for 1, 3 and 5 years overall survival (OS) in Lung cancer patients with OSA. The nomogram is valued to obtain the probability of 1, 3 and 5 years survival by adding up the points identified on the points scale for each variable. 

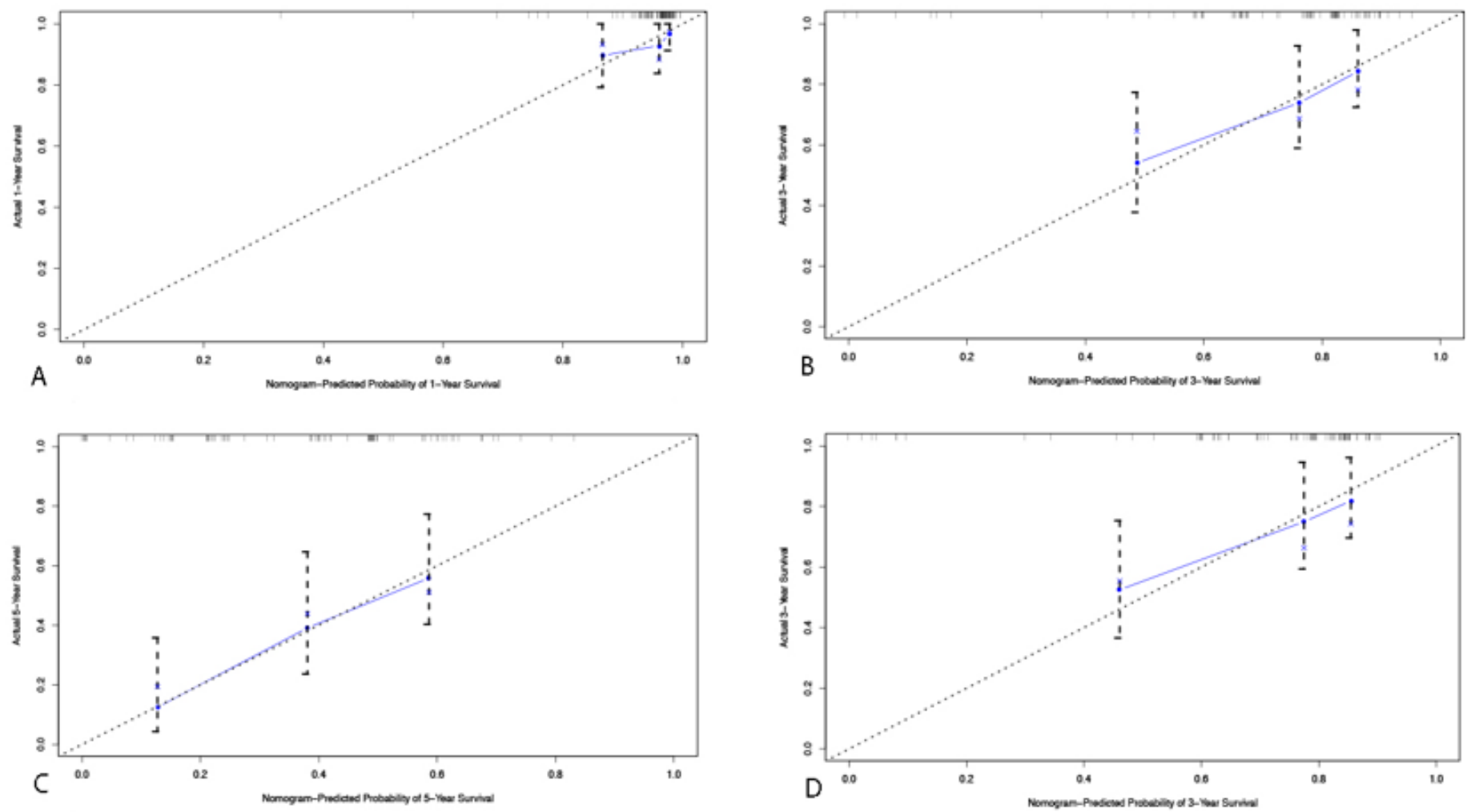

Figure 2

The calibration curve for predicting patient survival at A: 1 years, B: 3 years and C: 5 years in the development cohort and at D: 3 years in the validation cohort. Nomogram-predicted probability of overall survival is plotted on the $x$-axis; actual overall survival is plotted on the $y$-axis. 


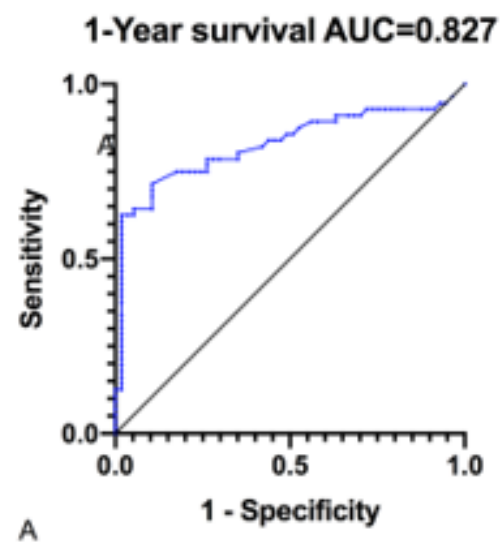

A

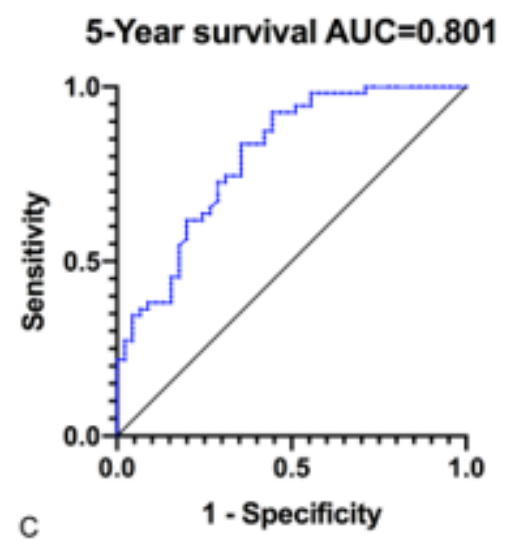

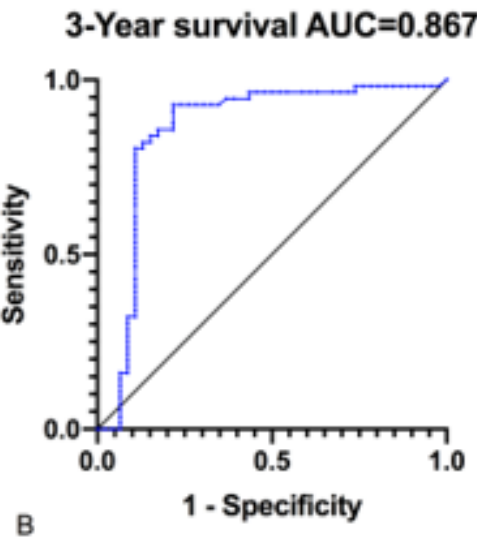

3-Year survival AUC $=0.863$

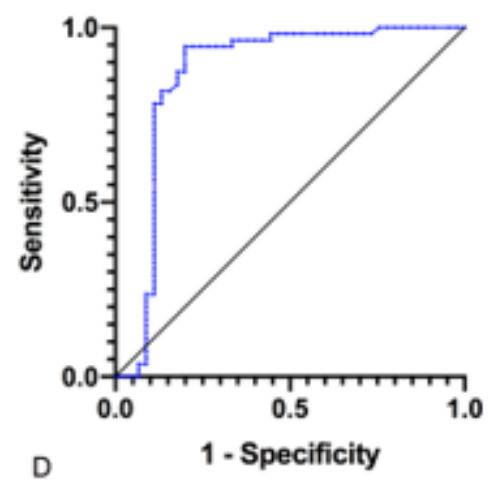

\section{Figure 3}

The ROC curve for predicting patient survival at A: 1 years, B: 3 years and C:5 years in the development cohort and at D: 3 years in the validation cohort. 

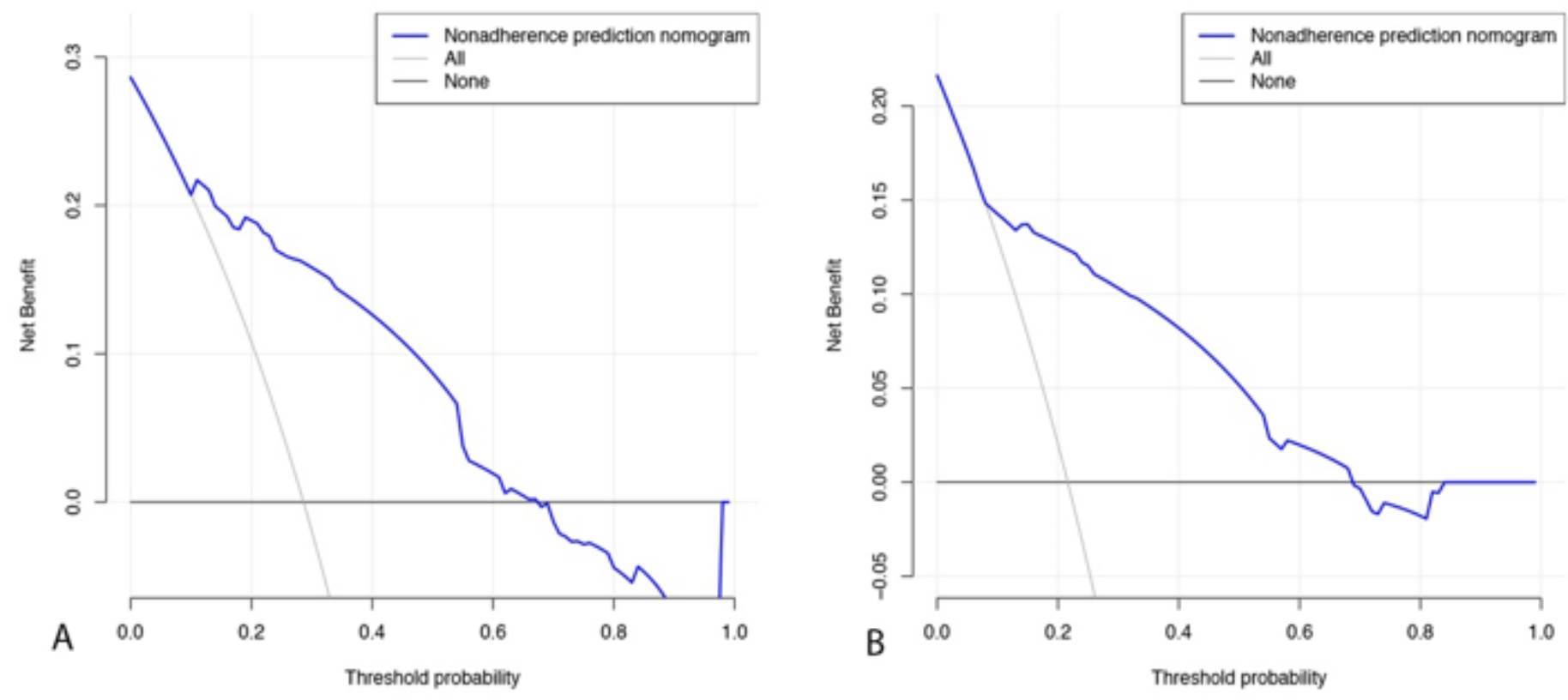

Figure 4

Decision curve analysis for overall survival. A: In the development cohort. B: In the validation cohort. The Black line: no effect of relevant independent factors. Gray line: effect of relevant independent factors. The Blue dashed line: the model of nomogram.
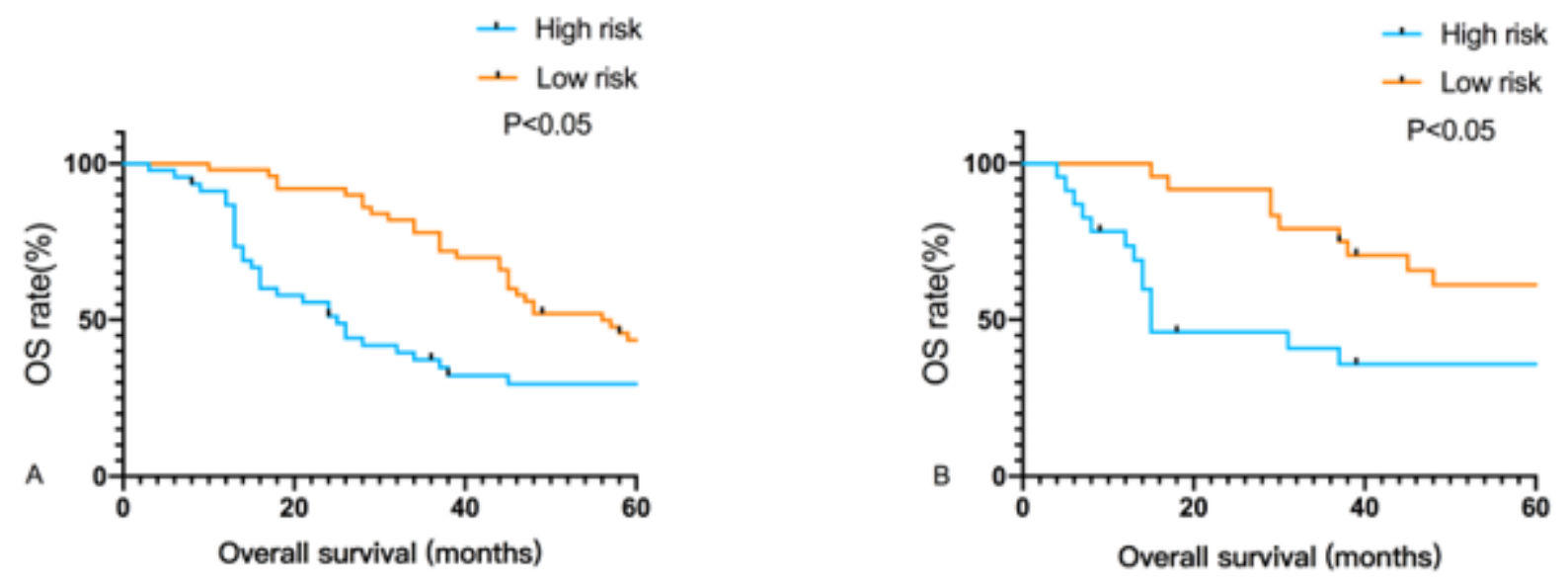

Figure 5

Kaplan-Meier survival curves of nomogram. A In the development cohort. B In the validation cohort 